MATEC Web of Conferences 53, 01036 (2016)

DOI: $10.1051 /$ matecconf/20165301036

(C) Owned by the authors, published by EDP Sciences, 2016

\title{
Functionality of Ventilated Facades: Protection of Insulation
}

\author{
Mikhail Petrichenko ${ }^{1}$, Tatiana Musorina ${ }^{1, \mathrm{a}}$, Elena Statsenko ${ }^{1}$, Anastasia Ostrovaia ${ }^{1}$ and Vladimir \\ Tarasov $^{1}$ \\ ${ }^{1}$ Peter the Great St.Petersburg Polytechnic University, Polytechnicheskaya 29, 195251, St.Petersburg, Russia
}

\begin{abstract}
This article discusses about methods of construction of the ventilated facades. The ventilated facade is not only the element of facing, it is the supporting structure. Their main objective - creation of air ventilating space between a facade and an external wall of the building. Moving of air in this gap protects a heater from destruction, interfering with a moisture congestion. In addition, the ventilated facade protect the building from aggressive influence of external environment, have a sound and thermal insulation properties. There are several problems of systems of the ventilated facades connected with an application of a heater. For more effective using it is necessary to minimize contact of a heater with environment.
\end{abstract}

\section{Introduction}

HVF - is a complex system consisting of a substructure, insulation, air gap and a protective screen, which is mounted on the outside of the main walls of the building. [1-11] They allow you to quickly and easily reconstruct the existing buildings and to increase its resistance to heat walling. They also comply with the requirements of the recently adopted heat and can be used for the construction of buildings, improve the appearance of the building, sound insulation, moisture conditions enclosing walls, resistance to weathering, and others. [13]. The cost of hinged ventilated facade substructure depends on the thickness of the insulation [5].

Mineral wool insulation in facade and roof structures subject to strong operational influences. Inside the fiber structure are constantly alternating processes: humidification - drying, freeze - thaw, mechanical vibration. In the Russian climate the most devastating are the processes of freezing and thawing damp mineral wool. The rate of destruction of the insulation is determined by the volume of incoming and freezing rain. The combination of effects after prolonged use leads to the fact that break down the organic binder is subjected to vibration fatigue fracture mineral fiber [12]. It should be borne in mind that most of the insulation in our conditions have become wet during transportation and installation. Insulation used in curtain wall systems must meet a number of requirements: it must be fire-resistant, durable, have good sound insulation qualities. It should have a sufficient density - from 80 to $100 \mathrm{~kg} / \mathrm{m} 3$. Since the air flow is separated small particle material - going emission fiber. When installing an illegal armed formation at a certain wind speed they can start to whistle and hoot, most often it occurs in places eddies of wind flows. Describes the phenomenon caused more long brackets for attaching external components and ductility of cotton. The system of ventilated facades require high quality components and, as mentioned earlier, a very high-quality installation, as corrosion of one or two fasteners can result in collapse of the entire façade. [9, 23-25]

\footnotetext{
${ }^{\text {a }}$ Corresponding author : flamingo-93@mail.ru
} 
One possible solution, the application of ventilated facades may be the development and introduction of new energy-saving technologies for these systems [10, 17-19]

The hinged ventilated facades of is the most multifunctional data element systems - a layer of air or an air gap. It is this layer performs both heat shield and blocking function. Additionally, when properly projected structure in this layer HVF moisture is removed, which is a waste product of people staying in the building and allocated in various household and industrial processes.

But it is also necessary to determine how much Ventfasad affect the thermal conductivity of the insulation. The main feature of insulation consisting of bonded mineral fibers - high air permeability. System through interfiber pores in a material permeable to air, gas, and liquid water, irrespective density of the material insulator. Some manufacturers believe most breathable wool her dignity: fibrous insulation materials do not interfere with the movement of vapor out through the exterior walls. But none SNIP does not allow the use of insulation and walling to dehumidify indoor air exist for this ventilation system. Upon contact with cold external sites wet insulation inside air condenses, wetting the insulation. Limit moisture condensation in the insulation can only design solutions that reduce the diffusion and convection currents flowing water [2-3]

Hydration wool comes from different sides, and the water-repellency fiber insulation does not reduce the volume of condensation water.

1. Moisturize from the outside. Facade cladding ventilated facade, consisting of separate elements, there is a gap (rusty), through which the rain and the cold air penetrate and moisturize the insulation system. From moisture completely protected even solid lining, as is always the possibility of defects installation, mechanical damage, the number of which increases with the square facing, the number of window frames and various frames.

2. Moisturize from the inside. In cold weather, a heater threatened moisture from the warm side. When carrying fencing have enhanced vapor permeability (porous concrete wall brick wall with a poor grouting, walling bulkhead slots, poorly executed, steam, attics), vaporous moisture from the premises condenses in cold regions insulation. Tall buildings have a high partial pressure of steam on the upper floors. In this case, the vapor barrier properties of the fence, even made of cast concrete, may not be enough, need more steam, $[1,15]$

With regard to the ventilated facade weight loss of mineral wool installed without wind and waterproof membrane, leads not only to a decrease in strength, thermal insulation properties, but also to a serious violation of the ecology of the environment and living space. For example, a nine-storey building with insulation Series 90, with an area of 1498 square meters of insulation. m requires 135 cubic meters. m of modern mineral wool density $74 \mathrm{~kg} / \mathrm{cu} . \mathrm{m}$. In the 25 years of operation of conventional building ventilation air flow can endure because of the skin venfasada $1875 \mathrm{~kg}$ fiber dust. These data convince appropriateness of the design of ventilated facades wind-hydroprotective membranes on the outer surface of the mineral wool. A more expensive solution - the use of panels of high density (above $150 \mathrm{~kg} / \mathrm{cu} . \mathrm{M}$ ), does not provide similar protection of insulation from external moisture and filtering, [4,20-22].

Warranty service life of 50 years, mineral wool can be obtained subject to the limitation (rationing) destructive factors. To do this, the system should be regulated to protect the insulation, working in the air gap of the facade:

1. Protection of the inner surface Minplita - severe restriction of moisture from the premises provided a high level of vapor barrier fence;

2. protection of outer surface Minplita - strict limitation of atmospheric moisture, air filtration, the loss of mineral fibers is ensured by the presence of wind-hydroprotective diffusion membrane.

The traditional objection to the use of wind-hydroprotective ventilated facade membrane systems is that "the presence of water vapor permeability of the membrane reduces the insulation system." Vapor-permeable membrane slightly, by $0.5 \%$, reduces the diffusion of water vapor through the multilayer structure of the outer walls with a ventilated air gap. Afraid to install a vapor barrier in a residential area due to lack of ventilation. At the same time over the fence in the heater can do a number of internal moisture from the premises, which can not cope with a membrane having a water vapor permeability of $1,000 \mathrm{~g} / \mathrm{sq}$. $\mathrm{m}$ per day. As a result, a "cost-effective" solution as the lack of 
ventilation in the room and the membrane in a ventilated gap leads to the inner insulation and moisture to eliminate its external protection. By limiting the admission of moisture from the premises membrane will display only the gaseous moisture which passes itself under adverse weather conditions - high humidity, fog and rain. Water vapor permeability of $1,000 \mathrm{~g} / \mathrm{sq}$. $\mathrm{m}$ per day maintains a heater in the equilibrium dry in all weather conditions. [14]

Application of wind - hydroprotective vapor barrier membrane and insulation systems with a ventilated gap will exclude from the selection criteria of insulation characteristics such as water absorption, air permeability, density, leaving only the thermal conductivity, dimensional stability, mechanical strength. [27]

Goals and objectives

The aim of the article is - taking into account the impact of the analysis of a ventilated facade on the insulating properties of the insulation.

To achieve this goal it is necessary to solve the following problems:

- Investigate the thermal insulation properties of walls with hinged ventilated facades with a shield and without protective screen;

- An analysis of studies on the thermal insulation of building materials walling considering shield;

Shown, that:

- There is a dependence of the density of the air permeability of the fibrous insulation; With this, the influence of a number of design features and climatic conditions on the longitudinal filtration of air in the insulation and heat-shielding properties of ventilated facades. [6]

\section{Materials and Methods}

\subsection{Types of mineral wool}

Thermal insulation for ventilated facade should have the following main functions: waterproof, high water vapor permeability, lack of strain in the winter, the most tightly against the wall. The main materials used for facade insulation - mineral wool, expanded polystyrene, extruded polystyrene foam, fiberglass materials.

For example, a heater as IZORUF is a semi-rigid mineral boards, based on - the rock. Because of this, the material can withstand temperatures up to 750 degrees without losing their acoustic and thermal insulating properties. Plates thus not deform or subside. The high degree of vapor permeability prevents the accumulation of water in the heat-insulating layer, ensuring its rapid evaporation. Among the materials produced on the basis of extruded polystyrene foam, it is possible to allocate Tepleks 35 . The low humidity of this material is provided by closed cell structure, which distinguishes it from other moisture-absorbent insulation. Tepleks 35 is not affected by temperature, it has a minimal deformation during thermal exposure. Antibacterial properties (resistance to rot) and chemical resistance allows the use of polystyrene in a corrosive environment. [14, 26]

In current practice as insulation material in the territory of Russia are widespread mineral wool based on basalt binder, as well as boards based on expanded polystyrene. In some parts of the building, such as caps and place of constant accumulation and retention of water used slabs of polystyrene, obtained by extrusion. At this historic moment, the current regulatory documentation did not reflect all the nuances of the use and production of such materials. For example, it is completely absent standards for durability of such products, the terms of service and operational requirements in different climatic conditions in Russia. [7, 8]

\section{Impact of ventilated facades in the mineral wool}

We find the thermal resistance of the wall

1. Consider the case where no shield 


$$
\alpha_{\text {int }}=10 \mathrm{~W} / \mathrm{M}^{2} \mathrm{~K}
$$

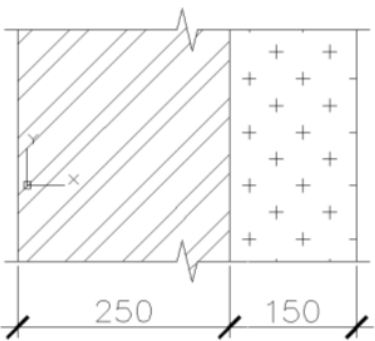

$$
\alpha_{\text {ext }}=20 \mathrm{~W} / \mathrm{M}^{2} \mathrm{~K}
$$

Figure 1. Cut the wall without a protective screen

Find the thermal resistance of the wall.

The resistance is given by:

Initial data:

$$
R=\frac{1}{\alpha_{i n t}}+\frac{1}{\alpha_{e x t}}+\frac{\delta_{\mathrm{K}}}{\gamma_{\mathrm{K}}}+\frac{\delta_{\mathrm{y}}}{\gamma_{\mathrm{y}}}
$$

The temperature inside the premises $\alpha_{\text {int }}=10 \mathrm{~W} /\left(\mathrm{M}^{2} \mathrm{~K}\right)$

The temperature of the outside $\alpha_{\text {ext }}=20 \mathrm{BT} /\left(\mathrm{m}^{2} \mathrm{~K}\right)$

Table 1. The original data for calculating

\begin{tabular}{|c|c|c|}
\hline & Thermal conductivity & Thickness \\
\hline silicate bricks & $\gamma_{\mathrm{K}}=0,7$ & $\delta_{\mathrm{K}}=0,25 \mathrm{M}$ \\
\hline Mineral wool & $\gamma_{\mathrm{y}}=0,07$ & $\delta_{\mathrm{y}}==0,15 \mathrm{M}$ \\
\hline
\end{tabular}

$$
\mathrm{R}=\frac{1}{10}+\frac{1}{20}+\frac{0.25}{0.7}+\frac{0.15}{0.07}=2.65 \mathrm{M}^{2} \mathrm{~K} / \mathrm{W}
$$

Conclusion: due to the fact that the external (cold) wall surface exposed to weathering, low thermal resistance of the fence. The construction of the wall does not provide the minimization of heat flow

2. In the presence of the screen (double façade)

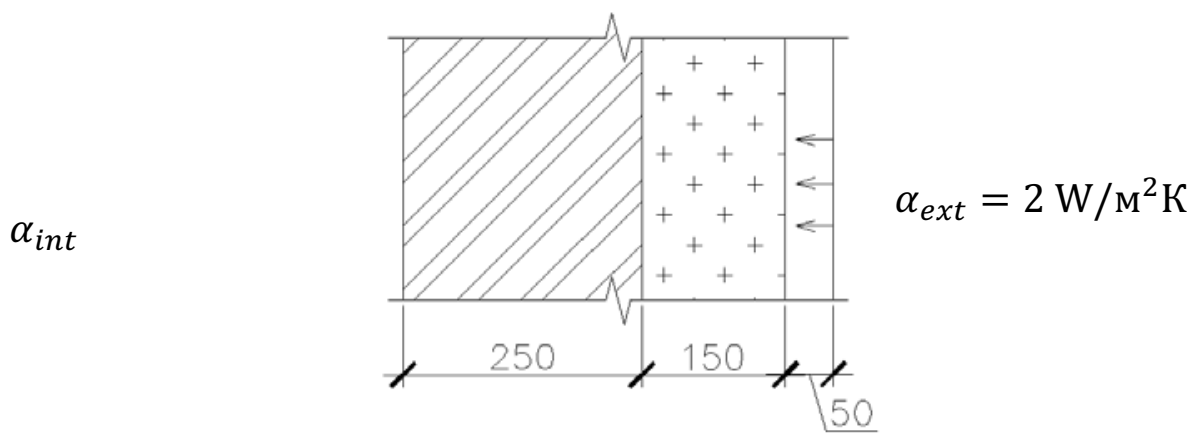

Fig 2. Incision wall based shield

The temperature inside the air gap will be equal to:

$$
\begin{gathered}
\alpha_{\text {ext }}=\frac{\alpha_{\text {air }}}{\delta_{\text {air layer }}}=\frac{0,1}{0,05}=2 \mathrm{~W} / \mathrm{M}^{2} \mathrm{~K} \\
\mathrm{R}=\frac{1}{10}+\frac{1}{2}+\frac{0.25}{0.7}+\frac{0.15}{0.07}=3,1 \mathrm{M}^{2} \mathrm{~K} / \mathrm{W}
\end{gathered}
$$

Conclusion: the introduction of HVF, thermal resistance increases. 


\section{Results and Discussion}

Consider the mass transfer of moisture in the insulation. The air gap as a pump pulls moisture from the insulation. It is necessary to move the dew point in the air gap is necessary that the air temperature is greater than the saturation temperature $\left(t_{B}>t^{\prime}\right)$, wherein, the water vapor: $t^{\prime}$ at this pressure $\mathrm{p}^{\prime}=\left(\frac{\mathrm{t}^{\prime}}{100}\right)^{4}$

Take the extreme case where the saturation temperature of the of insulation is on the edge, taking into account the protective screen

Heat flow stream is determined by:

$$
\mathrm{t}_{\mathrm{ext} 2}=\mathrm{t}_{\mathrm{c}}+\frac{\mathrm{r}_{2}}{\mathrm{r}_{1}}\left(\mathrm{t}_{\mathrm{ext} 1}-\mathrm{t}_{\mathrm{c}}\right)
$$

The temperature difference is equal to:

$$
\Delta \mathrm{t}=\Delta \mathrm{t}_{\text {ext }}=\mathrm{t}_{\text {ext2 }}-\mathrm{t}_{\text {ext1 }}
$$

Conclusion: The facade retains heat output in the wall

The evaporation of moisture from the surface of a heater in a free-convective flow in a viscositygravity flow regime described by the system of equations Eckert. In dimensionless form this system of equations is of the form:

$$
\begin{aligned}
& f^{\prime \prime \prime}+3 f f^{\prime \prime}-2 f^{\prime 2}+\theta=0, \\
& \theta^{\prime \prime}+3 \sigma f \theta^{\prime}=0,
\end{aligned}
$$

Where $\mathrm{f}=\mathrm{f}(\mathrm{y} / \delta)$ - the dimensionless function of the current, $\mathrm{y}$ - transverse coordinate (direction from a hot surface into a stream),

$\delta$ - thickness of the boundary layer lifting force,

$\theta$ - the concentration of a conservative and passive impurity,

$\sigma$ - the number of Prandtl for the diffusion of impurities, primes denote derivatives with respect $y / \delta$.

Limit conditions for the system Eckert put this way:

$$
f(0)=f^{\prime \prime}(0)=f^{\prime}(\infty)=0, \theta(0)-1=\theta(\infty)=0 .
$$

In this paper, for simplification replace the differential equation of pollutant transport algebraic condition "barotropic". Namely, let

$$
\theta=\beta f^{\prime 2}
$$

Where $\beta$ - coefficient of proportionality.

Then the first equation Eckert takes the form:

wherein.

$$
f^{\prime \prime \prime}+3 f f^{\prime \prime}-(2-\beta) f^{\prime 2}=0
$$

$$
\begin{gathered}
\text { Nont } f(0)=f^{\prime \prime}(0)=f^{\prime}(\infty)=0 \text { rivial solution of this equation is: } \\
f^{\prime}=u_{0}\left(1-F^{2}\right), F:=f / f_{0}, f_{0}:=f(\infty) .
\end{gathered}
$$

proved by: $\beta=5$,

$u_{0}$ - the speed of free-convection flow on the hot surface (as a fraction of the average speed), $f_{0}=\sqrt{2 u_{0} / 3}$ - dimensionless stream function (as a fraction of the flow).

Then, finally: 


$$
\begin{aligned}
& f=f_{0} \operatorname{th}\left(x u_{0} / y_{0}\right) \\
& u=u_{0} \operatorname{sech}^{2}\left(x u_{0} / y_{0}\right), \\
& \theta=\beta u_{0}^{2} \operatorname{sech}^{4}\left(x u_{0} / y_{0}\right)
\end{aligned}
$$

\section{Conclusions}

1. In the current practice as insulation material in the territory of Russia are widespread mineral wool based on basalt binder, as well as boards based on expanded polystyrene. Thermal protection is not dependent on the thickness of the insulation. All it related to the properties of the material itself. 2. As shown in the calculations based on a ventilated facade thermal resistance increases.

\section{References}

1. V.G Gagarin, AVOK, 2 (2005);

2. B.V. Gusev, V.A. Yezerskiy, P.V. Monasteries Industrial and civil construction, 1 (2005)

3. V.G. Gagarin V.V. Kozlov E.Y.Tsykanovsky AVOK, 2, 20-26 (2004)

4. S.N. Ovsyannikov T.S. Vyazova, 6, 20-28 (2013)

5. G.Radovic, , V.Murgul, N.Vatin, Applied Mechanics and Materials, 584-586, 564-569 (2014)

6. W. Guoa, X. Qiaoa, Y. Huanga, M. Fanga, X. Hanb. Energy and Buildings Volume In Press, Corrected Proof, 43-53 (2012).

7. Z. Xinhong, M Congyu., G. Pingdao, Energy Energy Procedia, 14, 1523-1527 (2012)

8. M. Petrichenko, X.Rakova, M. Vyatkin, , T. Musorina, , D. Kuznetsova, Applied Mechanics and Materials, 725-726, 1101-1106 (2015)

9. N.V. Nemov, V.Y.Olszewski, D.N. Tseitin Scientific and technical statements STU 4 (183), 295$301(2003)$

10. G. Radovic, , V. Murgul, , N .Vatin, Applied Mechanics and Materials, 584-586, 564-569 (2014)

11. A.S. Gorshkov Civil Engineering magazine, 1 (2010)

12. A.S Gorshkov., D.Y Popov. A.V. Glumov Civil Engineering magazine, 8 (18) (2010)

13. M.V. Knatko M.N.Efimenko, A.S. Gorshkov Civil Engineering magazine 2 (2008)

14. S.D. Maloedov, V.N. Vyguzov Building materials 5 (2001)

15. I. Ptuhina, T. Spiridonova, T. Musorina, Applied Mechanics and Materials, 725-726, 153-159 (2015)

16. A.F. Ostrovaja, M.R. Petrichenko, E.A. Stacenko, Applied Mechanics and Materials, 725-726 (2015).

17. T. Smirnova Architecture and Construction Requirements, 5 (2009)

18. V. Starodubtsev, S.V. Povetkin Industrial and Civil Engineering, 5 (2009)

19. A.A. Stepanov Building materials, 5 (2009)

20. E.T. Tazeeva, A.S. Gorshkov Vseros works. scientific and engineering. Conf. - SPb .: Publishing House of the Polytechnic University in 2011 (2011)

21. N.P. Umnyakova Architecture and Construction, 5 (2009)

22. D. Nemova, , V. Murgul, , V. Pukhkal, , A. Golik, , E. Chizhov, N. Vatin, Journal of Applied Engineering Science 12, 37-44 (2014)

23. N.I. Vatin D.V. Nemova The world of construction and real estate, 36, 1-4 (2010)

24. N. Mingottia, T. Chenvidyakarn, A.W. Woods, Energy and Buildings, 58, 237-249 (2013)

25. F. Marques da Silva, M. Gloria Gomes, A. Moret Rodrigues, Building and Environment, 87, 292$301(2015)$

26. N. Mingotti, T. Chenvidyakarn, A. W. Woods, Building and Environment, 46, 807-823 (2011)

27. A.S. Gorshkov, X.M. Rakova, T.A. Musorina, D.N. Tseytin, K.N. Agishev Construction of Unique Buildings and Structures, 4(31), 232-247 (2015) 